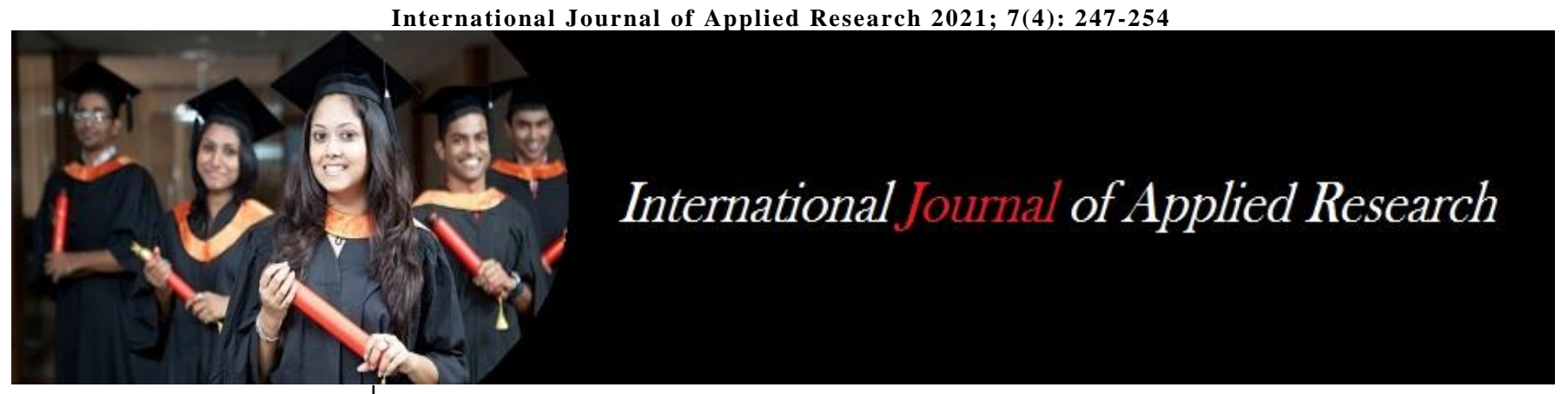

ISSN Print: 2394-7500

ISSN Online: 2394-5869

Impact Factor: 8.4

IJAR 2021; 7(4): 247-254

www.allresearchjournal.com

Received: 19-02-2021

Accepted: 23-03-2021

Subrata Sarkar

Department of Remote Sensing and GIS, Vidyasagar

University, Midnapore, West

Bengal, India

Jatisankar Bandyopadhyay Department of Remote Sensing and GIS, Vidyasagar University, Midnapore, West Bengal, India

Soumen Giri

Department of Remote Sensing and GIS, Vidyasagar

University, Midnapore, West Bengal, India
Corresponding Author: Subrata Sarkar

Department of Remote Sensing and GIS, Vidyasagar

University, Midnapore, West Bengal, India

\section{Spatio-Temporal analysis of forest conversion in contrasting LULC and vegetation extraction using spatial information southern part of Jangalmahal, West Bengal, India}

\author{
Subrata Sarkar, Jatisankar Bandyopadhyay and Soumen Giri
}

DOI: https://doi.org/10.22271/allresearch.2021.v7.i4d.8501

\section{Abstract}

Forest plays very important role in climate control and carbon sequestration. The study analyzed the spatio-temporal changes in forest cover and detects the factors influencing forest cover changes in southern Part of Jangalmahal using Remote Sensing and GIS techniques. In order to evaluate changes in forest, satellite images are collected from Landsat 7 ETM+ of 2000 \& Sentinel-2B 2020 are also preprocessed and classified. SRTM image was use for showing the topographic of the study area. The SVM classification techniques used to derive LULC maps from Landsat and Sentinel-2B images of each year in ENVI 5.3. The accuracy of classification is more than $80 \%$. LULC change matrix was performed to show the conversions of forest land to other Land Use and Land Cover classes. The LULC results shows that there was an increase trend in agricultural land and settlements are land use classes for decreasing of forest cover. Between 2000 and 2020 agricultural land increase $82.57 \mathrm{sqkm}$ $(18.22 \%)$ and settlement $51.58 \mathrm{sqkm}(11.38 \%)$. The vegetation indices, NDVI mean was calculated by remote sensing technique for each year. NDVI change matrix was calculated through Erdas Imagine and ArcGIS raster calculator reclassify tool for analyzing the rate of forest cover changes in this study area. After analyzing the NDVI change matrix the results demonstrate that between the 2000 and 2020 forest is 15676.11 hectors $(29.77 \%)$ decreased and 5922.10 hectors $(11.21 \%)$ increased, indicating that more forest cover decreased over time a trend that does not bode well for the maintenance of biodiversity in this area.

Keywords: Forest cover change, SVM, LULC, NDVI

\section{Introduction}

Generally we believe that forest is the environment's green blankets that conserve natural resources, protect and balance the ecosystem naturally. The total geographical area of forest in India is protected by $67.83 \mathrm{~m}$.ha. Which is $19.39 \%$ including mangroves, dense forest, and open forest. In this planet Earth, forest is most important to our life (Sarkar S, et al., 2019) ${ }^{[24]}$. Change in forest cover is an important, competitive, worldwide and growing mechanism, driven mainly by natural occurrences and anthropogenic activities, which in turn provide changes that impact the ecology of the biosphere (Butt A, et al., 2015) ${ }^{[6]}$. Deforestation and fragmentation of forests were mostly monitored by government programs because relevant data on continuous forest resource changes is needed to maintain policy decisions and sustainable management of forest schemes for reforestation purposes (Gadgil M, et al., 1983; Sader S, et al., 1985) ${ }^{[8,22]}$.

Remote sensing applications and GIS are widely used in natural resources and forest management processes. Remote sensing techniques and GIS tools have founded to be useful for evaluating the spatiotemporal changes in forest cover (Green K, et al., 1994; Rashid B, et al., 2018) [11, 20]. Change detection is the techniques of determining and monitoring the changes in forest cover by imagining at different times. Remote Sensing has been playing an important role in mapping and monitoring in forests cover changes (Forkuo E.K et al., 2012) [7]. The measure of change detection data modeling is well defined and the thematic changing information can be guidance to more tangible insights into the underlying process involving land cover and land use changes than the information obtained from continuous changes 
(Sarkar S, et al., 2019; Okorie F.C, 2012) ${ }^{[24,16]}$. The good quality of forest is the batter opportunity for socio-economic development and adjusting response to the challenge of climate change persuaded disasters (Bazgeer S, et al., 2007; Sakthivel R, et al., 2010) ${ }^{[3,23]}$.

Detection of forest cover change at spatial and temporal scale using satellite imageries such as Landsat series and Sentinel 2B is one of the most valuable contributions to natural resource management (Heckel K, et al., 2020; Negassa M.D, et al., 2020) ${ }^{[12,15]}$. Normalize Difference Vegetation Index or NDVI is one of the major indices to assess green and healthy vegetation. NDVI change matrix is one of the best change detection techniques for assess forest cover change (Wilson E.H, et al., 2002) ${ }^{[26]}$. In this area forest has been changed in past few decades due to lac of human and natural disturbances. For a sustainable forest resource management, it is necessary to estimate the rate of forest cover change on large spatial and temporal scales (Yismaw A, et al., 2014; Pylon P, 1988) ${ }^{[27,18]}$.

\section{Location of the Study Area}

The study area consists four major blocks of Jhargram district of West Bengal. Four blocks are Gopiballabpur I, Gopiballabpur II, Sankrail and Nayagram. The study area for the analysis lies between latitude $22^{\circ} 10^{\prime} 58.8^{\prime \prime} \mathrm{N}$ to $22^{\circ}$ $14^{\prime} 31.2^{\prime \prime} \mathrm{N}$ and longitude $84^{\circ} 43^{\prime} 1.2^{\prime \prime} \mathrm{E}$ to $87^{\circ} 13^{\prime} 26.4^{\prime \prime} \mathrm{E}$. The total geographical area is $1223.76 \mathrm{sqkm}$. The study area is the southern part of Jangalmahal area. (Figure: 1)

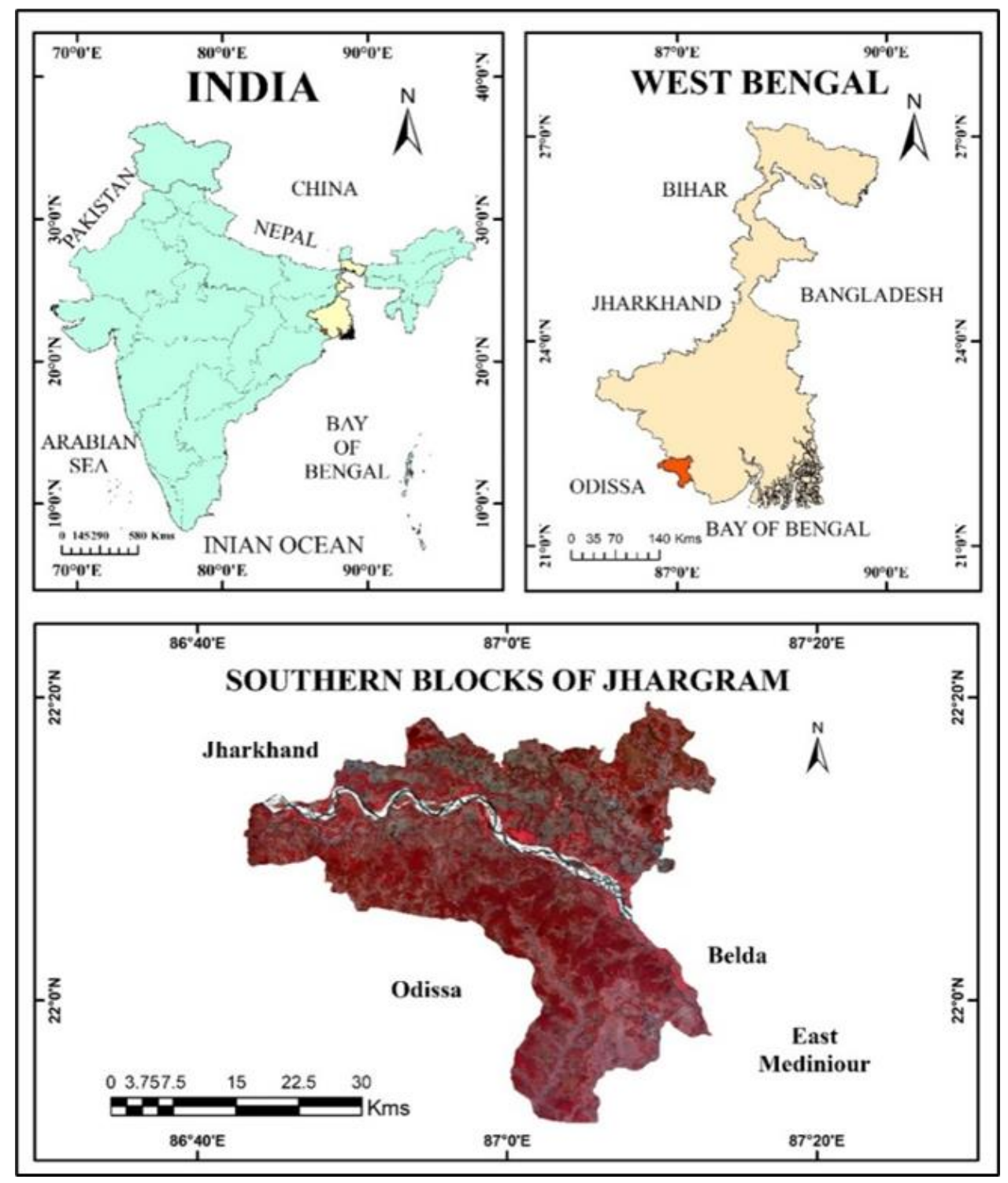

Fig 1: Location Map of study area

\section{Materials and Methods}

In this work to identify forest cover change area and conversion of forest area here used satellite images i.e. 2000 to 2020. Those satellites data are selected different Landsat series and also collected Sentinel 2B data of different time periods.

\section{Data Used}

Landsat data are collected from USGS-EROS (Earth Observation and Science Centre) and Sentinel 2B data are from ESA (European Space Agency). Landsat data has 30m and Sentinel $2 \mathrm{~B}$ has $10 \mathrm{~m}$ spatial resolution of multispectral bands.

\section{Pre-processing Image Correction}

Two types of image processing techniques are used in this analysis, the first is Radiometric Correction and the second is Atmospheric Correction. The value of the Digital number of pixels was converted to reflectance values in the radiometric correction (Mishra P.K, et al., 2020) ${ }^{[14]}$. Top 
Atmospheric Reflectance (TOA) is the effect of radiometric correction, but there are many atmospheric errors. After the success of the radiometric correction the final phase of preprocessing is atmospheric correction. The FLAASH
Atmospheric Correction technique is used for remove various atmospheric errors from satellite data such as reflectance, aerosol, water vapour, solar angle, etc. Methodology flow chart shown below in figure: 2 .

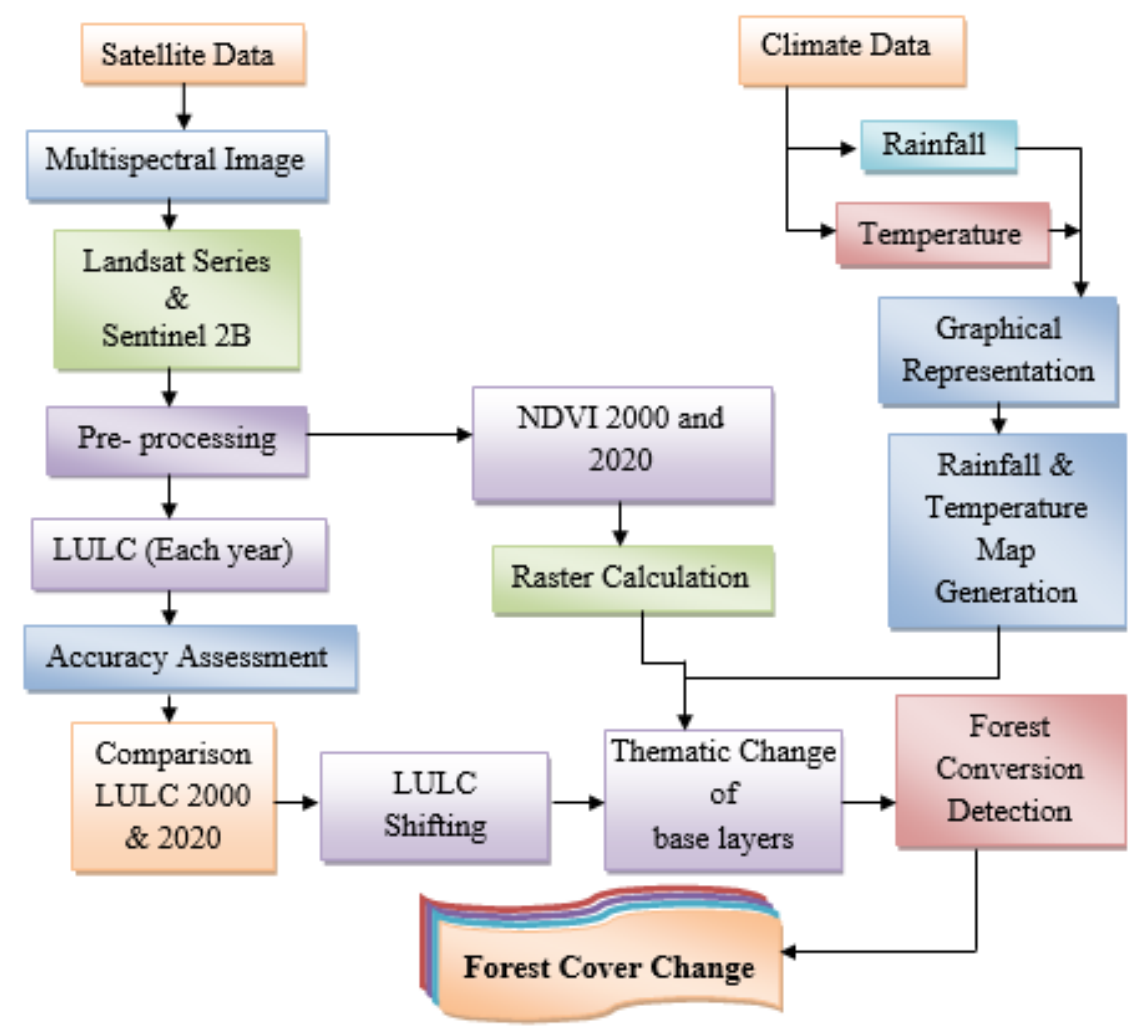

Fig 2: Methodology flow chart of the study area

\section{Climate}

The study area's atmosphere is highly humid and tropical. Monsoon rhythm is dominated characteristic in this region. The climate is tropical and the surface of the study area is characterized by hard rock upland laterites and flat alluvial plains. The area comes under Aw climatic types, based on the Köppen climate classification system. Aw refers to a tropical dry or savanna climate with a minimum of $60 \mathrm{~cm}$ (2.4 in) of precipitation and less than 4 percent of overall annual precipitation. The Rainfall and Temperature have shown in graph 1 and figure. 3 and 4.

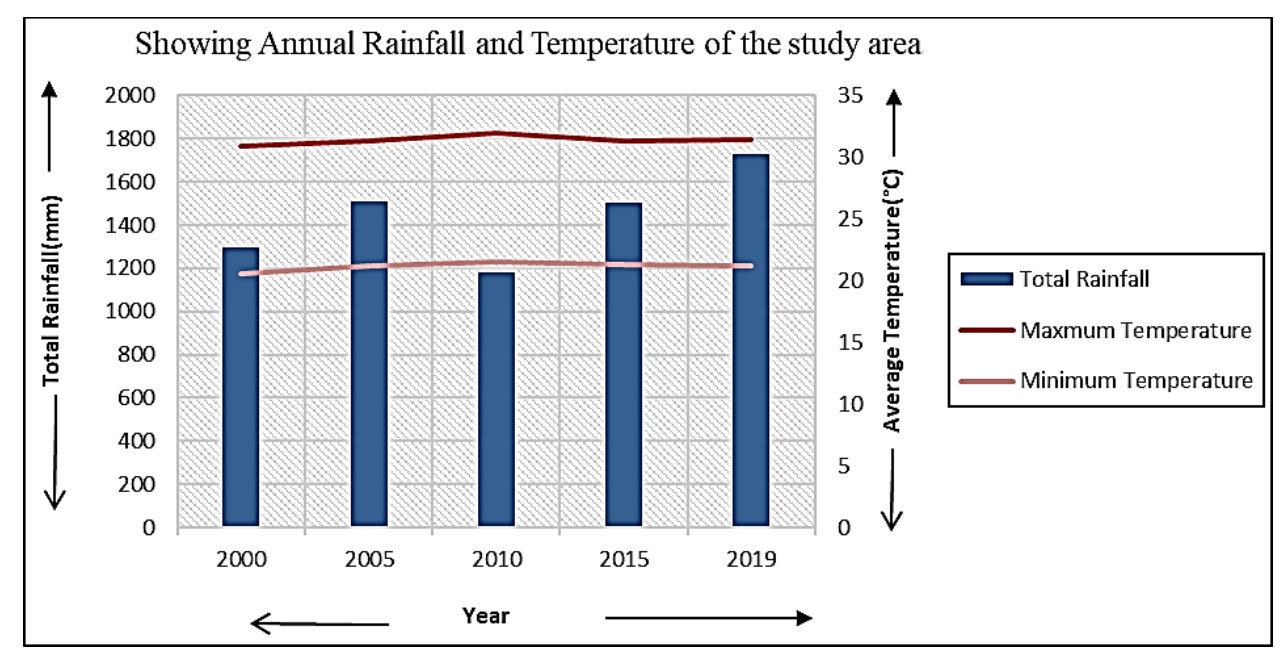

Graph 1: Annual Rainfall and Temperature of the study area

\section{Rainfall and Temperature}

Rainfall and temperature map has been prepared to indicate the study areas rainfall and temperature variation heavy, moderate and low. The highest rainfall occurs in Nayagram block it is closer to the Bay of Bengal. The lowest rainy months are January and December. The average rainfall of this area is around $1400 \mathrm{~mm}$. The temperature of this area is moderate to high. The average temperature of this area is around $33^{\circ} \mathrm{C}$. The temperature can reach as $46^{\circ} \mathrm{C}$ in the months of May and June during summer time (Prakash T.N, 2003) ${ }^{[17]}$. 


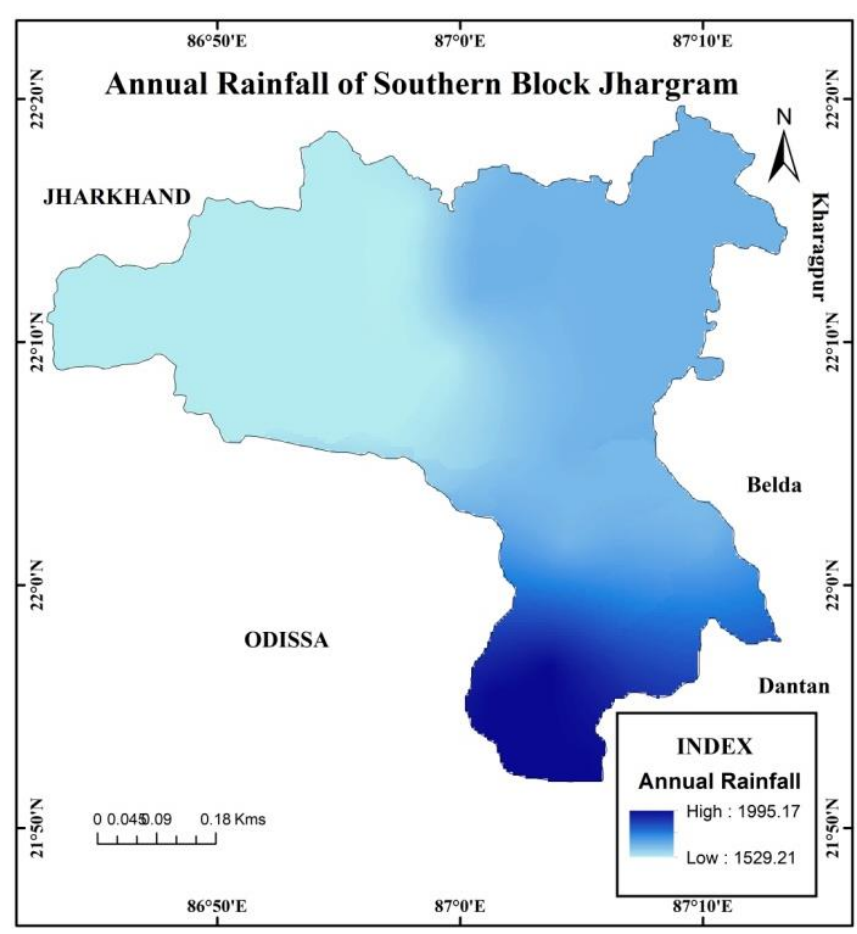

Fig 3: Annual Rainfall of the study area

\section{Result and Discussion}

Forest conversions could be established by the help of LULC change analysis. Various applications, various types of instruments and some mathematical equations are available to detect the changes of land use and land cover. Vegetation indexes are most widely used to measure or monitor changes in forest cover. Here, the extraction of vegetation using NDVI modeling is successfully completed using the spatial information technique.

NDVI: The Normalized Difference Vegetation Index (NDVI) is a measure that could be used in remote sensing to assess whether healthy green vegetation is detected at the target. On the other side, the pigment of tree leaves, chlorophyll, absorbs visible range strongly (from 0.4 to

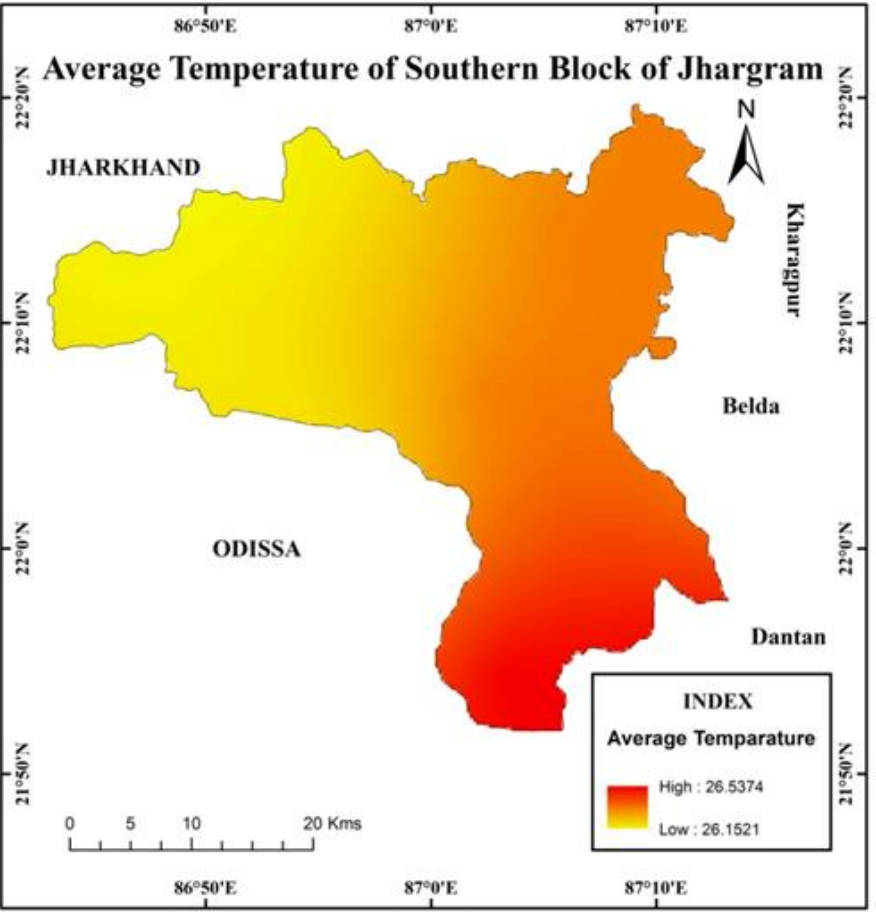

Fig 4: Average Temperature of the study area

$0.7 \mu \mathrm{m}$ ) and highly reflects near-infrared range (from 0.7 to $1.1 \mu \mathrm{m})$ (Giriraj A, et al., 2008) ${ }^{[10]}$.

LANDSAT/LC08/C01/T1_8DAY_NDVI for Landsat 8 NDVI image and image collection of LANDSAT/LE07/C01/T1_8DAY_NDVI Landsat 7 NDVI image. The used formula is

$$
\begin{gathered}
\text { var } n d v i=\text { colorized.reduce }(\text { ee } . \text { Reducer.mean }) ; \\
\operatorname{print}(n d v i)
\end{gathered}
$$

Here, after extracting the NDVI images, reclassification techniques were used and Forest Cover Change was calculated using the raster calculator process. These are shown in figure 5 and 6. 


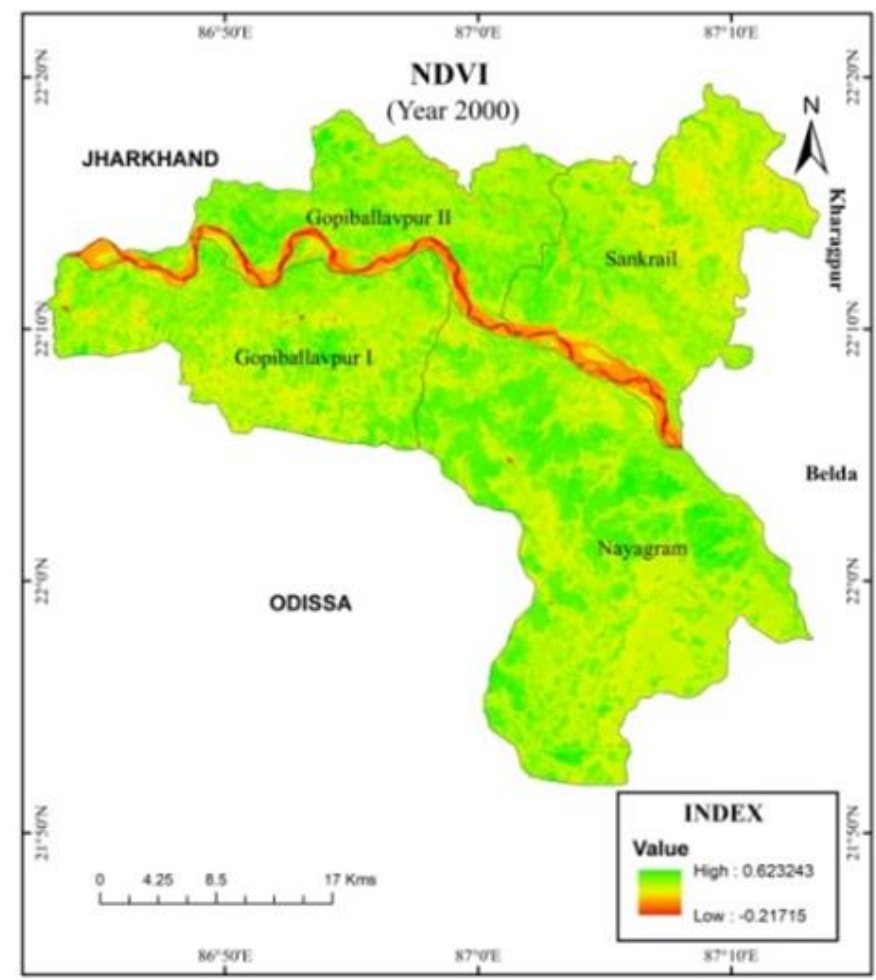

Fig 5: NDVI 2000

LULC: Southernmost portion of the Jangalmahal area is one of the richest forest regions in West Bengal. In this area, the major land cover feature is forestry, but some forest areas are shifted to other land use land cover features due to human inducement and some natural events, most of the cases forest is shifted to land use features such as

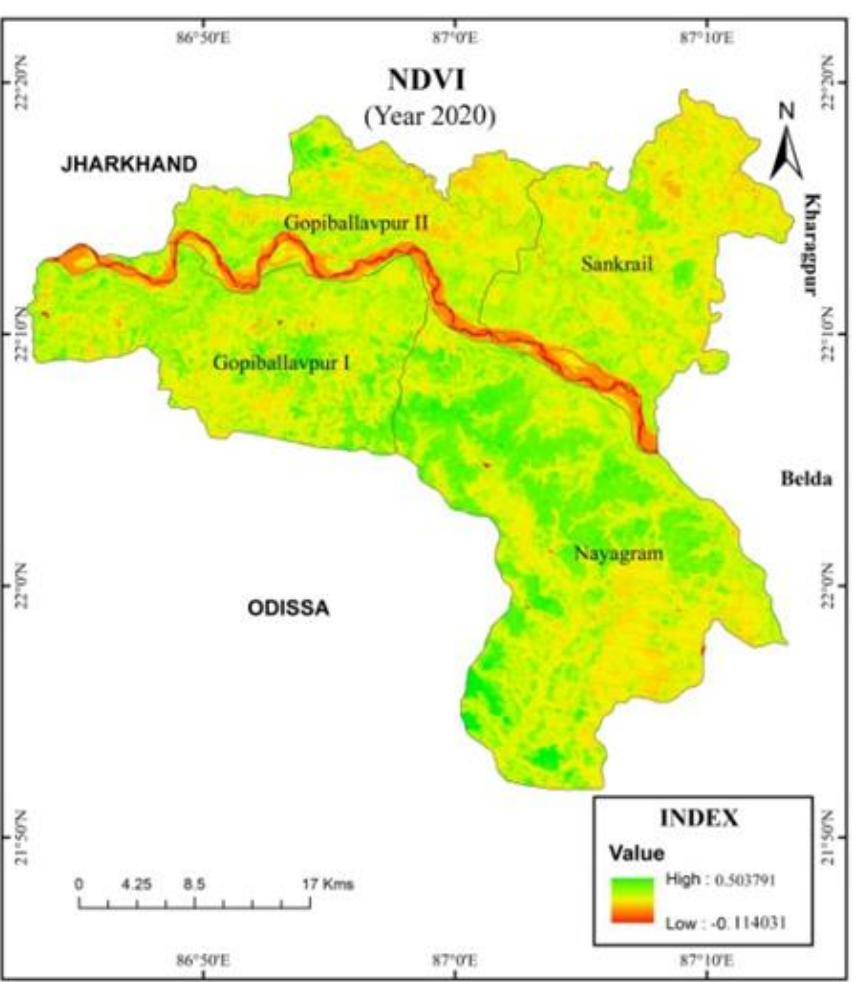

Fig 6: NDVI 2020

agricultural land. Most of the dense forests are found in Nayagram block and Gopiballabpur I block. Major agricultural activities are found in the interfluves region of the study area. Figure $7 \& 8$ are shows the LULC map of different year in the study area (Bojorquez-Tapia, L.A et al., 2001) ${ }^{[4]}$.

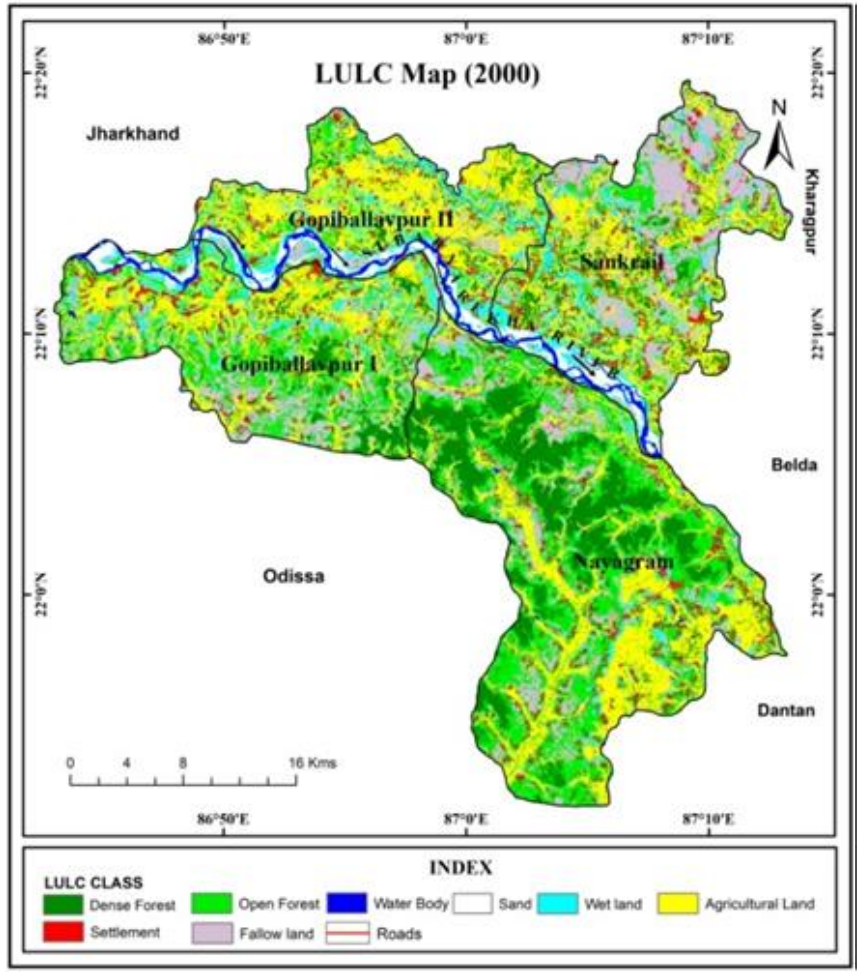

Fig 7: LULC 2000

Accuracy Assessment: The accuracy assessment shows the actual difference between the classification images in different time periods. Field verification and the Google Earth image are being used as reference data in this event.

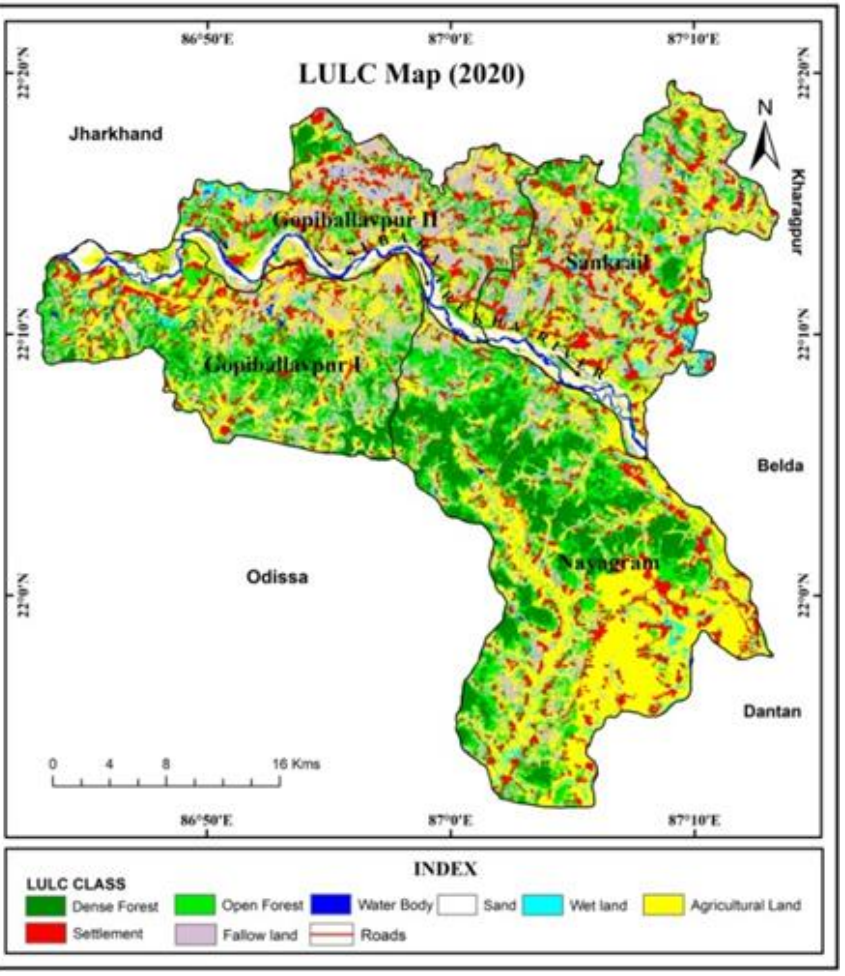

Fig 8: LULC 2005

The accuracy evaluation helps to verify the outcomes of the classification image and gives us assurance of the accuracy of the classification image (Bukhari S.K, et al., 2019) ${ }^{[5]}$. Classified pixels are compared with the real image in this 
analysis. Figure 9 to 13 shows the calculation of accuracy assessment of five LULC map.

This is how much the actual feature is correctly seen on the classified map on the study area. The formula for measuring the accuracy as mentioned below-

Producer Accuracy $=\frac{\text { Total Number of Coorect sample }}{\text { Total Number of Sample }} \times 100$
User accuracy is one of the essential methods by which the accurate of map users perspective. The user accuracy is mostly important that how much the classified class on the earth surface features. The formula for measuring user accuracy as defined bellow-

\section{User Accuracy $=\frac{\text { The total number of pixels in a catagory }}{\text { Total number of that catagory derived from the reference data }} \times 100$}

Overall accuracy used to measure the entire image of all classes the equation analysis bellow-

$$
\text { Overall Accuracy } \frac{\text { Total number of correct sample }}{\text { Total number of sample }} \times 100
$$

The Kappa coefficient is determined between the classification image and the reference data from a statistical test to be analyzed. The value range for the Kappa coefficient is -1 to 1 . The value of 0 indicates that the image of the classification is not accurate or very low on average. The Negative Kappa coefficient value of the classification image is poor than the average and near 1 implies that the classified image is better than the average (Gajbhiye $\mathrm{S}$, et al., 2012; Rasheed S, et al., 2009) ${ }^{[9,19]}$. The formula of Kappa Coefficient is defined below-

$$
\text { Kappa Coefficient }(k)=\frac{N \sum_{i=1}^{n} m_{i, i}-\sum_{n=1}^{n}\left(G_{i} C_{i}\right)}{N^{2}-\sum_{n=1}^{n}\left(G_{i} C_{i}\right)}
$$

Where,

$\mathbf{i}=$ is the number of class

$\mathbf{N}=$ is the total number of classified values especially in comparison with the actual values

$\mathbf{m}_{\mathbf{i}, \mathbf{i}}=$ is the number of value which belonging to the actual class $\mathbf{i}$ that also have been classified as class $\mathbf{i}$ (i.e., values found along the diagonal of the confusion matrix)

$\mathbf{C}_{\mathbf{i}}=$ is the total number of predicted values which belonging to class $\mathbf{i}$

$\mathbf{G}_{\mathbf{i}}=$ is the total numbers of actual values which belonging to class $\mathbf{i}$

\begin{tabular}{|c|c|c|c|c|c|c|c|c|c|c|}
\hline 2000 & $\begin{array}{l}\text { Dense } \\
\text { Forest }\end{array}$ & $\begin{array}{c}\text { Open } \\
\text { Forest }\end{array}$ & Agriculture & $\begin{array}{l}\text { Water } \\
\text { Body }\end{array}$ & Sand & $\begin{array}{l}\text { Fallow } \\
\text { Land }\end{array}$ & Settlement & Transport & Wet Land & User \\
\hline Dense Forest & 10 & 0 & 0 & 0 & 0 & 0 & 0 & 0 & 0 & 10 \\
\hline Open Forest & 0 & 9 & 1 & 0 & 0 & 0 & 0 & 0 & 0 & 10 \\
\hline Agriculture & 0 & 0 & 19 & 0 & 0 & 1 & 0 & 0 & 0 & 20 \\
\hline Water Body & 0 & 0 & 0 & 10 & 0 & 0 & 0 & 0 & 0 & 10 \\
\hline Sand & 0 & 0 & 0 & 0 & 10 & 0 & 0 & 0 & 0 & 10 \\
\hline Fallow Land & 0 & 0 & 0 & 0 & 0 & 10 & 0 & 0 & 0 & 10 \\
\hline Settlement & 0 & 0 & 0 & 0 & 0 & 0 & 10 & 0 & 0 & 10 \\
\hline Transport & 0 & 0 & 0 & 0 & 0 & 0 & 0 & 10 & 0 & 10 \\
\hline Wet Land & 0 & 0 & 5 & 0 & 0 & 0 & 0 & 0 & 5 & 10 \\
\hline Producer & 10 & 9 & 25 & 10 & 10 & 11 & 10 & 10 & 5 & 100 \\
\hline
\end{tabular}

Table 1: Showing (a) \& (b) accuracy assessment of the year 2000

(b)

\begin{tabular}{|c|c|c|c|c|c|c|c|c|c|}
\hline User Accuracy & 100 & 90 & 100 & 100 & 100 & 100 & 100 & 100 & 50 \\
\hline Producer Accuracy & 100 & 90 & 95 & 100 & 100 & 90 & 100 & 100 & 100 \\
\hline
\end{tabular}

Overall accuracy $93 \%$

Kappa Coefficient (k) 0.92

Table 2: Showing (c) \& (d) accuracy assessment of the year 2020

\begin{tabular}{|c|c|c|c|c|c|c|c|c|c|c|}
\hline 2020 & $\begin{array}{l}\text { Dense } \\
\text { Forest }\end{array}$ & Open Forest & Water Body & Sand & Wet Land & Agriculture & Settlement & Transport & Fallow Land & User \\
\hline Dense Forest & 10 & 0 & 0 & 0 & 0 & 0 & 0 & 0 & 0 & 10 \\
\hline Open Forest & 0 & 9 & 0 & 0 & 0 & 0 & 0 & 0 & 1 & 10 \\
\hline Water Body & 0 & 0 & 7 & 0 & 1 & 2 & 0 & 0 & 0 & 10 \\
\hline Sand & 0 & 0 & 1 & 9 & & & 0 & 0 & 0 & 10 \\
\hline Wet Land & 0 & 0 & 0 & 0 & 4 & 6 & 0 & 0 & 0 & 10 \\
\hline Agriculture & 0 & 0 & 0 & 0 & 0 & 19 & 0 & 0 & 1 & 20 \\
\hline Settlement & 0 & 0 & 0 & 0 & 0 & 0 & 10 & 0 & 0 & 10 \\
\hline Transport & 0 & 0 & 0 & 0 & 0 & 0 & 0 & 10 & 0 & 10 \\
\hline Fallow Land & 0 & 0 & 0 & 0 & 0 & 1 & 0 & 0 & 9 & 10 \\
\hline Producer & 10 & 9 & 8 & 9 & 5 & 28 & 10 & 10 & 11 & 100 \\
\hline
\end{tabular}

(c) 
(d)

\begin{tabular}{|c|c|c|c|c|c|c|c|c|c|}
\hline User Accuracy & 100 & 90 & 70 & 90 & 40 & 95 & 100 & 100 & 90 \\
\hline Producer Accuracy & 100 & 90 & 80 & 90 & 50 & 71.14 & 100 & 100 & 90.09 \\
\hline
\end{tabular}

Overall Accuracy $86 \%$

Kappa Coefficient (k) 0.83

\section{Comparison Forest Conversion and LULC Change 2000 to 2020}

The Support Vector Machine (SVM) classification method has been used to LULC classification analyze for the forest conversions in the study area (Zou X, et al., 2011; McFeeters S.K, 2013) ${ }^{[28,13]}$. Satellite Images have been classified into nine classes of land use and land cover. This include dense forests, open forests, water bodies (including natural and artificial water bodies), sand, agricultural land, fallow land, settlement and transport (roads). Land use and land cover shows in figure 8 that the comparison forest conversion in between 2000 to others year image at twentyyears period within the southern parts of the Jangalmahal forest area. The area showed a rapid conversion of forest land to agricultural land, settlement (Verburg P.H, et al., 2006) ${ }^{[25]}$

The forest of study area has undergone extensive degradation during the two decades. Spatial pattern of forest dynamics suggests three main reason of forest clearing including broad scale conversion and degradation of forest of the study area. For this time period conversion of dense forest and open forest due to agricultural land hectors (18.22\%), settlement 5158.86 hector $(11.38 \%)$, fallow land 3934.361 hectors $(8.68 \%)$, wet land 863.27 hectors $(1.90 \%)$ conversion from forest land. The statistical data show that rapidly increase if agricultural land is the main reason for conversion forest lands and settlement also a main reason for conversion of forest. The overall accuracy for the year 2020 is $86 \%$ and kappa coefficient is $0.83 \%$. (Figure: 9)

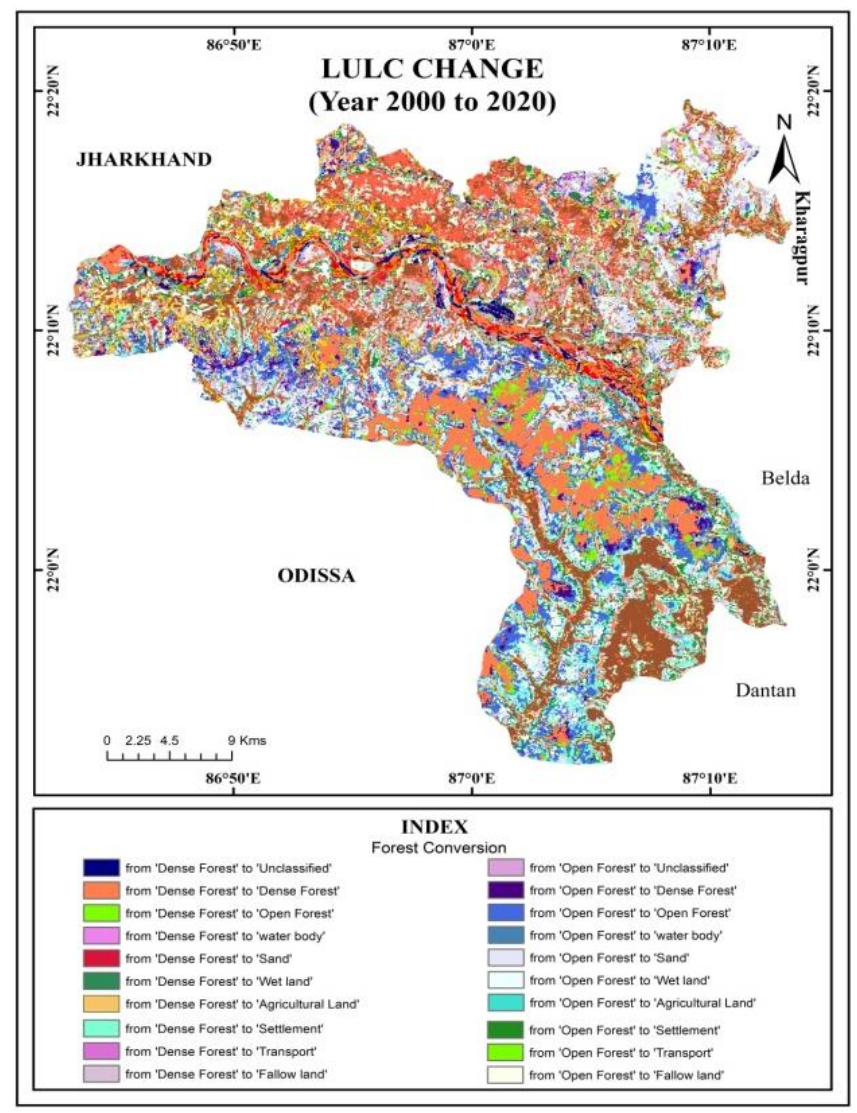

\section{Forest Cover Change 2000 to 2020}

The calculated change is 15676.11 hectors $(29.78 \%)$ decreased of the forest cover and 5922.10 hectors (11.21\%) increased of the forest cover in just two decades. Most of the forest was decreased in Gopiballabhpur II, Sankrail and Nayagram block. Grwoing rate is higher in Gopiballabhpur I block as compared to other three blocks. The total changes of forest cover are 21598.21 hectors (including gain and loss of forest). This result shows that changing of forest cover is a serious concern in this study area. (figure: 10)

Table 3: Area of forest Change in 2000-2020

\begin{tabular}{|c|c|}
\hline \multicolumn{2}{|c|}{ Change of Forest from 2000 to 2020 } \\
\hline Loss & 15676.11 hectors \\
\hline Gain & 5922.10 hectors \\
\hline Total Change & 21598.21 hectors \\
\hline
\end{tabular}

\section{Conclusion}

The results of the study proved that improvements in remote sensing image analysis are a powerful method for evaluating the assessment of forest conversion and analysis of forest cover change. A major environmental issue observed in the study area is forest cover change. The analysis of changes in spatiotemporal forest cover for the years 2000 to 2005, 2010, 2015 and 2020 showed that negative forest cover changes occurred in the study area. We can identify the analysis from 2000 to 2020 that 15676.11 hectares $(29.78$ percent) decreased forest cover and increased agricultural land and settlement were also the major factors of forest cover change in this region. Accurate and updated land cover change information is necessary for understanding main reason and environmental consequences of such changes, while remote sensing has the capability of monitoring such changes. The classification achieved in this study produces an overall accuracy that fulfills the minimum accuracy threshold and also Google Earth Engine NDVI mean gives the better result to accurately identify the forest cover changes. From using these techniques, we can find out the future scenario of forest cover change and forest land conversion of this study area.

\section{References}

1. Ashraf A. Changing hydrology of the Himalayan watershed. Current Perspectives in Contaminant Hydrology and Water Resources Sustainability, 2013, 978-953.

2. Atesoglu A, Tunay M. Spatial and temporal analysis of forest cover changes in the Bartin region of northwestern Turkey. African Journal of Biotechnology 2010;9(35).

3. Bazgeer S, Sharma PK, Mahey RK, Hundal SS, Sood A. Assessment of land use changes using remote sensing and GIS and their implications on climatic variability for Balachaur watershed in Punjab, India. Desert 2007;12(2):139-147.

4. Bojorquez-Tapia LA, Diaz-Mondragon S, Ezcurra E. GIS-based approach for participatory decision making

Fig 9: Forest Change in 2000-2020 
and land suitability assessment. International Journal of Geographical Information Science 2001;15(2):129-151.

5. Bukhari SK. Spatio-Temporal Land Use / Land Cover Dynamics In Ningli Watershed Of Jehlum Catchment In Kashmir Valley, North Western Himalaya Using Remote Sensing \& Gis 2019;5:850-857.

6. Butt A, Shabbir R, Ahmad SS, Aziz N. Land use change mapping and analysis using Remote Sensing and GIS: A case study of Simly watershed, Islamabad, Pakistan. The Egyptian Journal of Remote Sensing and Space Science 2015;18(2):251-259.

7. Forkuo EK, Frimpong A. Analysis of forest cover change detection, International Journal of Remote Sensing Applications 2012;2(4).

8. Gadgil M, Prasad SN, Ali R. Forest management and forest policy in India: a critical review. Social Action 1983;33(2):127-155.

9. Gajbhiye S, Sharma SK. Land use and land cover change detection of Indra river watershed through remote sensing using multi-temporal satellite data. International Journal of Geomatics and Geosciences 2012;3(1):89-96.

10. Giriraj A, Irfan-Ullah M, Murthy MSR, Beierkuhnlein C. Modelling spatial and temporal forest cover change patterns (1973-2020): A case study from South Western Ghats (India). Sensors 2008;8(10):6132-6153.

11. Green K, Kempka D, Lackey L. Using remote sensing to detect and monitor land-cover and land-use change. Photogrammetric engineering and remote sensing 1994;60(3):331-337.

12. Heckel K, Urban M, Schratz P, Mahecha MD, Schmullius C. Predicting Forest Cover in Distinct Ecosystems: The Potential of Multi-Source Sentinel-1 and-2 Data Fusion. Remote Sensing 2020;12(2):302.

13. McFeeters SK. Using the normalized difference water index (NDWI) within a geographic information system to detect swimming pools for mosquito abatement: A practical approach. Remote Sensing 2013;5(7):35443561.

14. Mishra PK, Rai A, Rai SC. Land use and land cover change detection using geospatial techniques in the Sikkim Himalaya, India. The Egyptian Journal of Remote Sensing and Space Science 2020;23(2):133143.

15. Negassa MD, Mallie DT, Gemeda DO. Forest cover change detection using Geographic Information Systems and remote sensing techniques: a spatiotemporal study on Komto Protected forest priority area, East Wollega Zone, Ethiopia. Environmental Systems Research 2020;9(1):1.

16. Okorie FC. A spatio-temporal analysis of deforestation in Epe and its environs (Lagos). International Journal of Science, Environment and Technology 2012;1(5):548562.

17. Prakash TN. Land suitability analysis for agricultural crops: a fuzzy multicriteria decision making approach. ITC, 2003.

18. Pylon P. An enhanced classification approach to change detection in semiarid environments. Photogrammetric Engineering and Remote Sensing 1988;54(12):17091716.

19. Rasheed S, Venugopal K. Land suitability assessment for selected crop in Vellore district based on agroecological characterization, 2009, 616-628.
20. Rashid B, Iqbal J. Spatiotemporal change detection in forest cover dynamics along landslide susceptible region of Karakoram Highway, Pakistan. ISPRS Annals of Photogrammetry, Remote Sensing \& Spatial Information Sciences 2018;4(3).

21. Ren C, Chen L, Wang Z, Zhang B, Xi Y, Lu C. Spatiotemporal changes of forests in northeast China: Insights from landsat images and geospatial analysis. Forests 2019;10(11):937.

22. Sader SA, Joyce AT, Waide RB, Lawrance W. Monitoring tropical forests from satellite and aircroft platforms: some limitations and new approaches (No. 40682), 1985.

23. Sakthivel R, Manivel M, Raj NJ, Pugalanthi V, Ravichandran N, Anand VD. Remote sensing and GIS based forest cover change detection study in Kalrayan hills, Tamil Nadu. Journal of Environmental Biology, 31(5 Supplement), 2010, 737-747.

24. Sarkar S, Acharyya N, Bandyopadhyay J. Spatial Distribution and Changing Scenario of Green Space using Geospatial Techniques in Jangalmahal Area, Paschim Medinipur and Jhargram District, West Bengal, India, 2019.

25. Verburg PH, Overmars KP, Huigen MG, de Groot WT, Veldkamp A. Analysis of the effects of land use change on protected areas in the Philippines. Applied Geography 2006;26(2):153-173.

26. Wilson EH, Sader SA. Detection of forest harvest type using multiple dates of Landsat TM imagery. Remote Sensing of Environment 2002;80(3):385-396.

27. Yismaw A, Gedif B, Addisu S, Zewudu F. Forest cover change detection using remote sensing and GIS in Banja district, Amhara region, Ethiopia. International Journal of Environmental Monitoring and Analysis 2014;2(6):354.

28. Zou X, Shang Z, Odeh IO, Chen Y, Li J. Comparative Analysis on Spatio-Temporal Land Use and Land Cover (LULC) Characteristics in Three Asia Cities. In 2011 International Conference on Internet Computing and Information Services. IEEE, 2011, 179-182. 